\title{
Etiology of primary spontaneous pneumothorax
}

\author{
Roberto de Menezes Lyra',2
}

1. Serviço de Cirurgia Torácica, Hospital do Servidor Público Estadual de São Paulo, São Paulo (SP) Brasil.

2. Instituto de Assistência Médica ao Servidor Público Estadual - IAMSPE São Paulo (SP) Brasil.

Submitted: 12 September 2015. Accepted: 18 December 2015

Study carried out in the Serviço de Cirurgia Torácica do Hospital do Servidor Público Estadual de São Paulo and at the Instituto de Assistência Médica ao Servidor Público Estadual - IAMSPE São Paulo (SP) Brasil.

\section{INTRODUCTION}

Primary spontaneous pneumothorax is usually quantified and diagnosed in the ER by means of routine chest X-rays. ${ }^{(1,2)}$ However, it is not always easy to identify emphysematous bullae on routine chest X-rays. Emphysematous bullae are found in approximately 15\% of cases and are primarily located on the apical margins of the affected lung lobes. ${ }^{(3)}$

Currently, HRCT is more sensitive than routine chest $X$-rays for the diagnosis of apical emphysematous lesions, which are found in approximately $80 \%$ of all patients with primary spontaneous pneumothorax. ${ }^{(4,5)}$ In contrast, the prevalence of paraseptal emphysema in such patients is only $3 \% .^{(6)}$

\section{PATHOGENESIS}

The pathogenesis of primary spontaneous pneumothorax can be best understood by understanding emphysematous lung lesions.

The anatomical lesion known as a bleb was first described in 1947 by Miller, who established an anatomical distinction between a bleb and a bulla (bullous emphysema). ${ }^{(7)}$

Later, in 1967, Reid divided bullous emphysema, which causes bullae, into three types: type I, a small amount of hyperinflated lung tissue that is narrow (pedunculated) and contains no lung parenchyma; type II, a relatively smaller amount of hyperinflated lung tissue that is broad (sessile) and usually contains vanishing lung; and type III, a large amount of hyperinflated lung tissue extending to the pulmonary hilum, with ill-defined margins and vanishing parenchyma in each bulla. ${ }^{(8)}$

Chest CT has greatly contributed to the description of lung disease. ${ }^{(9)}$
For a better description of the aforementioned emphysematous lung lesions, a glossary of terms for thoracic imaging is required.

\section{Bleb}

The word bleb is translated to Portuguese as vesícula enfisematosa subpleural (i.e., subpleural emphysematous vesicle). A bleb is caused by alveolar rupture, which allows air to travel through the interlobular septum that divides the secondary pulmonary lobules to the subpleural region. The subpleural region is displaced, and a subpleural emphysematous vesicle (i.e., a bleb) is thus formed. Unlike a bulla, which is a distal acinar (or paraseptal) emphysematous lung lesion, the displacement caused by subpleural interstitial emphysema is generally small in size, i.e., $1-2 \mathrm{~cm}$ in diameter (Figure 1 ).

On chest CT scans, a bleb appears as a thin-walled cystic air space contiguous with the pleura. However, the use of the term bleb by radiologists is discouraged because the distinction between a bleb and a bulla is arbitrary and of little clinical importance.

\section{PULMONARY EMPHYSEMA}

Pulmonary emphysema is characterized by irreversible enlargement of the airspaces distal to the terminal bronchiole, accompanied by alveolar wall destruction.

On CT scans, emphysema appears as focal areas or regions of low attenuation, usually without visible walls. In the case of panacinar emphysema, decreased attenuation is more diffuse. Emphysema is usually classified according to the part of the acinus that is predominantly affected, being didactically divided into centriacinar (centrilobular) emphysema, panacinar (panlobular) emphysema, 
distal acinar (paraseptal) emphysema, and irregular emphysema associated with fibrosis.

\section{Centriacinar or centrilobular emphysema}

Proximal emphysema is designated centriacinar or centrilobular emphysema; however, it is more commonly termed simply emphysema.

Centrilobular emphysema is characterized by destroyed centrilobular alveolar walls and enlargement of respiratory bronchioles and associated alveoli. It is the most common form of emphysema in cigarette smokers.

In cases of centrilobular emphysema, spontaneous pneumothorax is usually more severe because it is associated with an underlying lung disease, being designated secondary spontaneous pneumothorax and possibly leading to severe respiratory failure.

CT findings are centrilobular areas of decreased attenuation, usually without visible walls, of nonuniform distribution and predominantly located in the lung apices.

\section{Panacinar or panlobular emphysema}

When emphysema affects the entire acinus, it is designated panacinar or, less commonly, panlobular emphysema.

\section{Distal acinar or paraseptal emphysema}

When emphysema is distal, affecting primarily the margins of the lung lobes, it is designated distal acinar or paraseptal emphysema, which is the form of emphysema that is most closely related to primary spontaneous pneumothorax.

Although paraseptal emphysema is multiform and can affect various portions of the lung lobes, it primarily affects the lung apices. The major subtypes of paraseptal emphysema are described below.

\section{Bulla/bullae}

A bulla (i.e., a subpleural emphysematous bulla) is an airspace measuring more than $1 \mathrm{~cm}$-usually several centimeters-in diameter, sharply demarcated by a thin wall that is no greater than $1 \mathrm{~mm}$ in thickness.

On CT scans, a bulla appears as a rounded focal lucency or area of decreased attenuation bounded

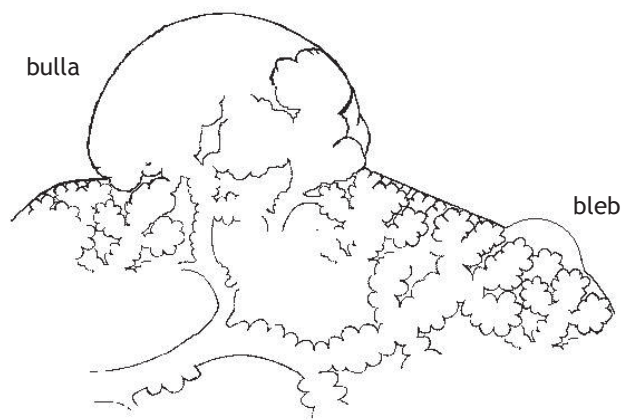

Figure 1. Schematic illustration of the anatomy of emphysematous lung lesions, representing a bleb and a bulla. by a thin wall, occurring predominantly in the lung apices (Figure 2).

\section{Bullous emphysema}

Multiple bullae can coalesce, characterizing bullous emphysema. Bullous destruction of the lung parenchyma is frequently associated with other signs of pulmonary emphysema (centrilobular or paraseptal emphysema).

\section{Irregular emphysema associated with fibrosis}

Absence of "obvious fibrosis" was historically regarded as an additional criterion for pulmonary emphysema. However, the validity of that criterion has been questioned because some interstitial fibrosis can be present in emphysema secondary to cigarette smoking.

\section{PATHOPHYSIOLOGY}

Distension of an emphysematous bulla leads to an extreme thinning of its structure (Figure 3 ).

The absence of pleural mesothelial cells on histological examination has been demonstrated by scanning electron microscopy, occurring primarily on the thin outer surface of type I bullae and in some areas on the surface of type II bullae. ${ }^{(10)}$ Therefore, distension of emphysematous bullae is due to a reduction in the surface tension of their walls, and this can be explained by Laplace's law. ${ }^{(11)}$ In addition, there is evidence of a congenital etiology; however, the pathogenesis of bullae remains controversial. ${ }^{(12)}$

\section{ANATOMY}

Bullae are found in approximately $85 \%$ of all patients with primary spontaneous pneumothorax undergoing surgery (Figure 4). ${ }^{(13,14)}$ However, there is no consensus in the literature regarding the anatomical classification of emphysematous lung lesions on the basis of surgical

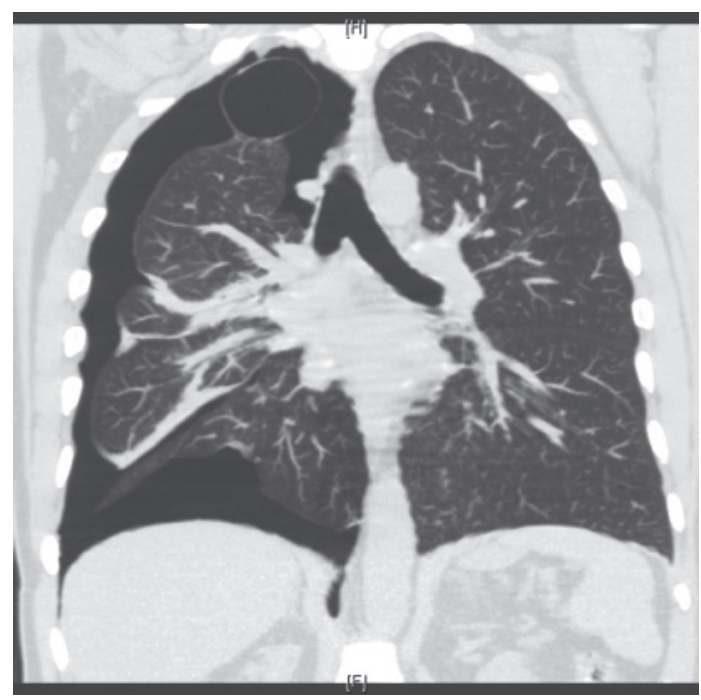

Figure 2. Coronal CT scan of the chest showing a bulla located in the right lung apex and accompanied by pleural adhesion. 
findings. During surgical exploration, the most common findings are as follows:

A. normal lung

B. apical lung scarring, primary spontaneous pneumothorax possibly being caused by a small

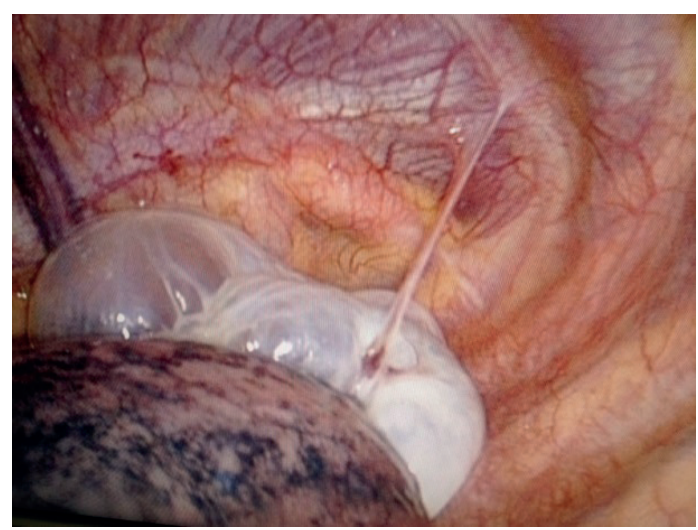

Figure 3. Video-assisted thoracoscopic surgery image of a bulla showing extreme thinning in the left lung apex and accompanied by pleural adhesion. bronchioloalveolar fistula surrounded by fibrotic tissue and approximately $1 \mathrm{~mm}$ in diameter

C. single or multiple blebs smaller than $2 \mathrm{~cm}$ in diameter

D. single or multiple bullae (forming a cluster) larger than $2 \mathrm{~cm}$ in diameter in a single lung segment

E. giant bulla(15)

F. multiple bullae in one or more lung lobes

G. multiple bilateral bullae

H. Iobar emphysema

I. recurrent pneumothorax, which can be accompanied by multiseptated, multiform membranous pleuropulmonary adhesions in the region where the bullae are located

J. multiloculated membranous chronic pneumothorax that can affect most of the pleural cavity

K. spontaneous hemopneumothorax related to rupture of cord-shaped vascularized pleuropulmonary adhesions during lung collapse (Figure 3)(16)

\section{SURGERY}

Currently, the vast majority of bullae are resected by video-assisted surgery with a surgical stapler (Figure 5).

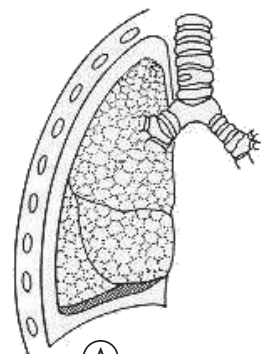

(A)

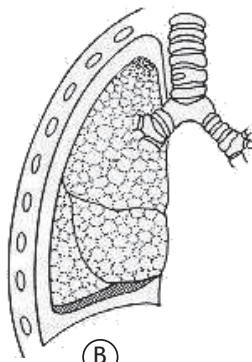

(B)

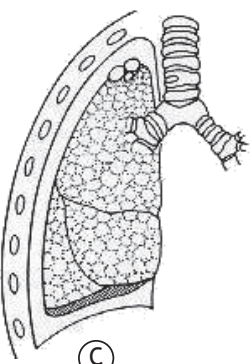

(C)

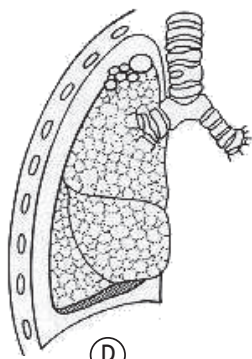

(D)

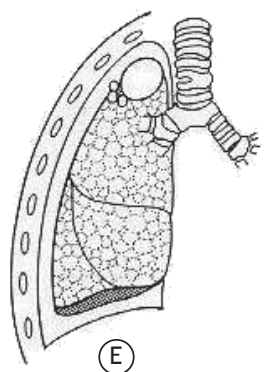

(E)
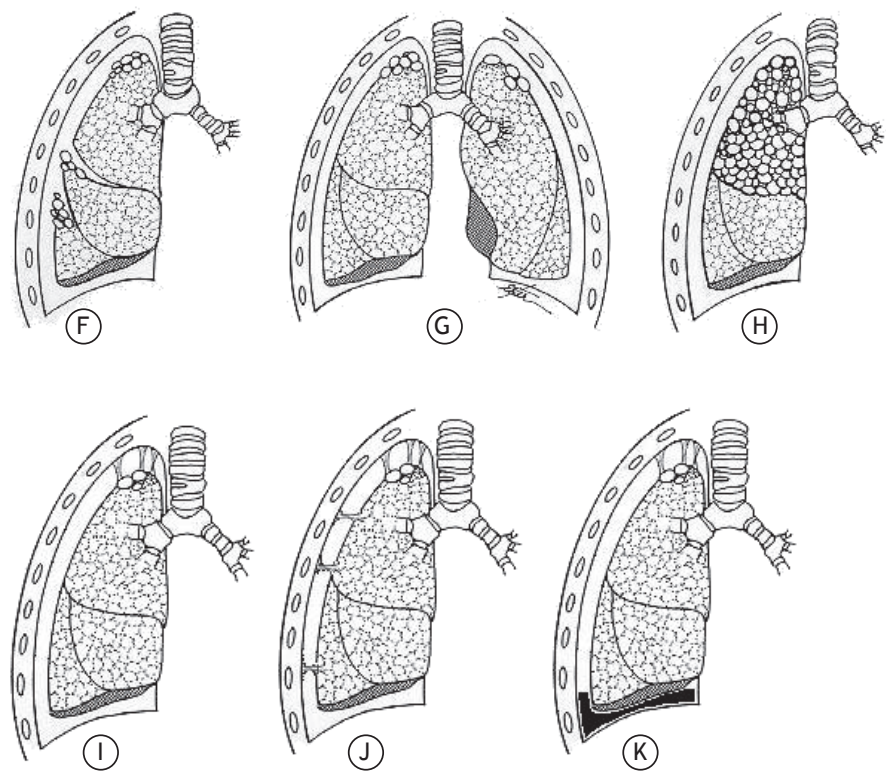

Figure 4. Schematic illustration of the types of emphysematous lung lesions. A: normal lung; B: apical lung scarring; C: small bleb; D: bulla; E: giant bulla; F: multiple bullae; G: multiple bilateral bullae; H: lobar emphysema; I: recurrent pneumothorax with multiform membranous pleuropulmonary adhesions; J: multiloculated membranous chronic pneumothorax; and K: spontaneous hemopneumothorax (the last three being accompanied by pleural adhesions). 


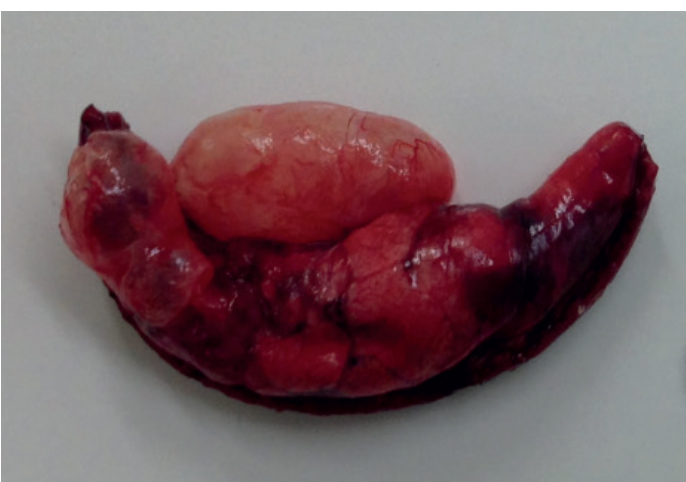

Figure 5. Lung specimen obtained by video-assisted surgery and showing bullae.

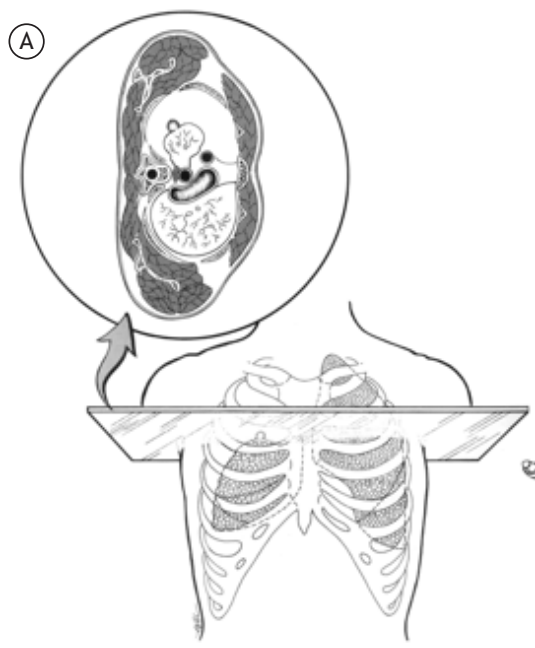

The use of CT in the preoperative period allows the identification of the emphysematous bullae (Figure 5). Currently, the vast majority of subpleural emphysematous bullae is visualized and resected video-assisted thoracic surgery with a surgical stapler. The staple line should preferably be positioned in healthy parenchyma or in an area without bullous emphysema (Figure 6). Therefore, the possibility of air leak in the immediate postoperative period is minimized. However, new emphysematous lesions (as seen on CT scans) have been reported to appear at the staple line during late follow-up in $37.1 \%$ of cases, and it has been suggested that this is a risk factor for recurrent primary spontaneous pneumothorax in the late postoperative period. $(17,18)$

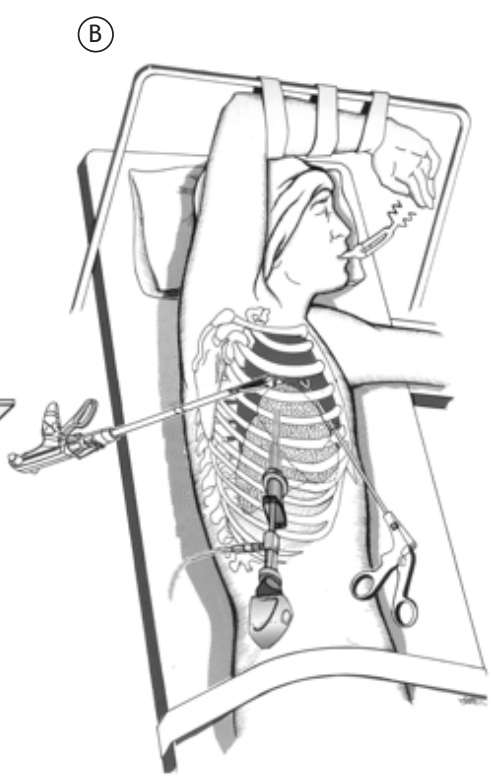

Figure 6. In A, schematic illustration of a cross-sectional CT scan used in the preoperative identification of emphysematous bullae. In $B$, the positioning of the required equipment for video-assisted thoracic surgery.

\section{REFERENCES}

1. Kelly AM, Weldon D, Tsang AY, Graham CA. Comparison between two methods for estimating pneumothorax size from chest $X$-rays Respir Med. 2006;100(8):1356-9. http://dx.doi.org/10.1016/j. rmed.2005.11.022

2. Bobbio A, Dechartres A, Bouam S, Damotte D, Rabbat A, Régnard JF, et al. Epidemiology of spontaneous pneumothorax: gender-related differences. Thorax. 2015;70(7):653-8. http://dx.doi.org/10.1136/ thoraxjnl-2014-206577

3. Silva $\mathrm{Cl}$, Marchiori E, Souza Júnior AS, Müller NL; Comissão de Imagem da Sociedade Brasileira de Pneumologia e Tisiologia Illustrated Brazilian consensus of terms and fundamental patterns in chest CT scans. J Bras Pneumol. 2010;36(1):99-123. http://dx.doi. org/10.1590/S1806-37132010000100016

4. Lesur O, Delorme N, Fromaget JM, Bernadac P, Polu JM. Computed tomography in the etiologic assessment of idiopathic spontaneous pneumothorax. Chest. 1990;98(2):341-7. http://dx.doi.org/10.1378/ chest.98.2.341

5. Bense L, Lewander R, Eklund G, Hedenstierna G, Wiman LG Nonsmoking, non-alpha 1-antitrypsin deficiency-induced emphysema in nonsmokers with healed spontaneous pneumothorax, identified by computed tomography of the lungs. Chest. 1993;103(2):433-8. http://dx.doi.org/10.1378/chest.103.2.433

6. Araki T, Nishino M, Zazueta OE, Gao W, Dupuis J, Okajima Y, et al. Paraseptal emphysema: Prevalence and distribution on $\mathrm{CT}$ and association with interstitial lung abnormalities. Eur $\mathrm{J}$ Radiol. 2015;84(7):1413-8. http://dx.doi.org/10.1016/j.ejrad.2015.03.010

7. Miller WS. The Pleura. In: Miller WS, editor. The Lung. 2nd ed Springfield, IL: Charles C. Thomas; 1947. p.145-58.

8. Reid L. Bullae. In: Reid L. The pathology of emphysema. London: Lloyd-Luke Medical Books; 1967. p.211-40.

9. Hansell DM, Bankier AA, MacMahon H, McLoud TC, Müller NL, Remy J. Fleischner Society: glossary of terms for thoracic imaging. Radiology. 2008;246(3):697-722. http://dx.doi.org/10.1148/ radiol.2462070712

10. Ohata M, Suzuki H. Pathogenesis of spontaneous pneumothorax With special reference to the ultrastructure of emphysematous bullae. Chest. 1980;77(6):771-6. http://dx.doi.org/10.1378/ chest.77.6.771

11. Oliveira MA, Alves FT, Silva MV, Croti UA, Godoy MF, Braile DM. Concepts of basic physics that every cardiovascular surgeon should know. Part 1-mechanics of fluids Rev Bras Cir Cardiovasc. 2010;25(1):1-10. http://dx.doi.org/10.1590/S010276382010000100006

12. Lichter I, Gwynne JF. Spontaneous pneumothorax in young subjects A clinical and pathological study. Thorax. 1971;26(4):409-17. http:// dx.doi.org/10.1136/thx.26.4.409

13. Vanderschueren RG. The role of thoracoscopy in the evaluation and management of pneumothorax. Lung. 1990;168 Suppl:1122-5. http:// 
dx.doi.org/10.1007/BF02718252

14. Rivas de Andrés JJ, Torres Lanzas J. Thoracoscopy and spontaneous pneumothorax. Ann Thorac Surg. 1993;55(3):811. http://dx.doi org/10.1016/0003-4975(93)90317-B

15. Sharma N, Justaniah AM, Kanne JP, Gurney JW, Mohammed TL. Vanishing lung syndrome (giant bullous emphysema): $\mathrm{CT}$ findings in 7 patients and a literature review. J Thorac Imaging. 2009;24(3):22730. http://dx.doi.org/10.1097/RTI.0b013e31819b9f2a

16. Kim ES, Kang JY, Pyo CH, Jeon EY, Lee WB. 12-year experience of spontaneous hemopneumothorax. Ann Thorac Cardiovasc Surg. 2008;14(3):149-53.

17. Chou SH, Li HP, Lee YL, Lee JY, Chiang HH, Tsai DL, et al. Videoassisted thoracoscopic surgery for postoperative recurrent primary spontaneous pneumothorax. J Thorac Dis. 2014;6(1):52-5.

18. Tsuboshima $K$, Nagata $M$, Wakahara $T$, Matoba $Y$, Matsumoto $S$, Maniwa Y. Relationship between postoperative bulla neogenesis at the staple line and the resected lung volume in primary spontaneous pneumothorax. Gen Thorac Cardiovasc Surg. 2015;63(10):572-5. http://dx.doi.org/10.1007/s11748-015-0568-1 